\title{
EVALUATION CRITERIA FOR THE RESPIRATORY FUNCTION OF THE DIVERS
}

\author{
Tamara STANCIU \\ "Diving Center", Constanţa, Romania \\ tamara.stanciu@navy.ro \\ Cecilia ADUMITRESI \\ "Ovidius" University, Faculty of Medicine, Constanţa, Romania \\ cadumitresi@yahoo.com
}

\begin{abstract}
The respiratory effort in hyperbaric conditions is of particular nature, leading to an increase of the respiratory flow of the diver and to the change of their pulmonary volumes. There are important criteria in the selection process of the most suitable divers. Some of these criteria are related to the respiratory function. In order to evaluate the divers respiratory function an examination of the pulmonary volumes is performed in regards to their variations measured by spirometry, of the increased oxygen consumption in hyperbaric conditions and of the production of carbon dioxide during the unitary dive at the depth of work using air as a respiratory mixture. The physical and physiological phenomena involved in the hyperbaric respiration have been studied in cooperation with "Ovidius" University of Constanta, Faculty of Medicine. A specific medical method of evaluation of the pulmonary ventilation, spirometry, the measurement of forced expiratory volume in the first second of a forced expiration, Tiffneau index, have been adapted to the under pressure breathing environment. The parameters have been studied as experimental determinations on diver groups, during simulated diving, using air as a respiratory mixture, at $50[\mathrm{mH} 2 \mathrm{O}]$ in the Hyperbaric Complex of the Diving Centre
\end{abstract}

KEYWORDS: Spirometry, FEV1, TIFFNEAU index, Rate of Oxygen Consumption

\section{Introduction}

The influence of the respiratory gases during the diving performed in hyperbaric condition represent important risk factors for the divers. With increasing depth (pressure) the gas becomes denser and produces an increase in the resistance to flow of the conducting airways. The volume of the anatomic dead space is also altered. Measurements of the pulmonary volumes, and of their changes, of oxygen consumption and carbon dioxide production, for each of the tested subject, during the diving, represent important data for this interdisciplinary study conducted in collaboration with the Faculty of Medicine of "Ovidius" University. 
Flow resistance and static lung load are the two main causes of breathing restriction induced by the underwater breathing apparatus. Respiratory flow resistance is due to the density of the gas flow passing through the tubing, the holes and the hoses of the diving equipment. When the density of the gas increases a higher pressure must be provided in order to maintain the flow of the gas at the same value.

The diver must produce a higher depression during inspiration and a higher pressure to produce expiration. If pulmonary ventilation rises with increasing exercise level the intensity of the physical effort even a higher depression must be provided to keep the gas flow at the same value. Due to the fact that the respiratory muscles are the ones creating the effort in the intrapulmonary pressure, there is a moment when these pressure gradients that induce inspiration and expiration cannot be raised any further. At this point, the carbon dioxide, waste product of the metabolic processes, is not properly removed its blood partial pressure raises, causing the symptoms of hypercapnia.

The partial pressure of the gases depends on the depth of the diving and as a consequence, the component gases of the respiratory mixture might reach critical values of their partial pressures. A reduced vital capacity of the lungs associated with a reduced pulmonary compliance predispose for the pulmonary rupture during free ascending and theoretically to the obstruction of the respiratory passages with a raise in the blocked gas fraction and all of these predispose to barotraumas (Tetzloff, Bettinghausen, Renter, Heller, \& Leplow, 1997).

Changes of the volumetric participation of the gaseous components of the respiratory mixtures greatly influence the ability of the diver's respiratory function. Therefore it is necessary to know the evolution of oxygen consumption and carbon dioxide production for each tested subject under resting conditions and sustained effort on the surface and during the diving.

\section{Aims of the Study}

For carrying out the study the research team has proposed the following:

- Testing and analysing FEV1 from the spirometric graphics.

- Testing and analysing the TIFFNEAU index for each of the tested subjects.

- Testing and analysing oxygen consumption from the expired air, according to the gas composition and the intensity of physical activity, in both conditions, at surface pressure and hyperbaric environment.

- Testing and analysing the carbon dioxide from the expired air related to the gas composition, intensity of the physical activity, in both conditions, at surface pressure and hyperbaric environment.

Vital capacity (VC) represents the maximal amount of air that can be ventilated during a maximum amplitude respiration and its value is about $3500-4600$ $\mathrm{ml}$ with variation based on gender, age, physical training, and physical activity. Vital capacity can be calculated as a sum of tidal volume (TV), inhaled reserve volume (IRV), and expiratory reserve volume (ERV) (Boron \& Boulpaep, 2005).

FEV1, forced expiratory volume exhaled during the first second of a forced breath normally represents $70-80 \%$ from the value of the vital capacity. FEV1 depends on the individual's vital capacity, respiratory muscles force and the permeability of the respiratory airways (Degeratu, Petru, Georgescu \& Ioniţă, 2008).

Tiffeneau index or the index of bronchial permeability represents the proportion of vital capacity that an individual is able to expire in the first second of the forced expiration and an 
important indicator in the evaluation of the human respiratory function and can be calculated with the formula:

$$
\begin{gathered}
\mathrm{TF}=\mathrm{FEV} 1 / \mathrm{VC} \\
T F=\frac{V E M S}{V C} \cdot 100 \%(\mathrm{John}, 2011)
\end{gathered}
$$

Maximal oxygen consumption with a rest value of about $200-250 \mathrm{ml} / \mathrm{min}$ is one of the main parameters that mark the differences among trained and untrained individual responses to the physical effort. During the physical effort the maximal oxygen consumption can reach more than $4000 \mathrm{ml} / \mathrm{min}$. Muscle cells use the oxygen to renew the ATP amounts in order to produce the necessary amount of energy for the muscles contraction. The maintenance of the muscle contraction for longer periods depends on the continuous ATP renewal. All the processes involved in the ATP production depend on an increased cells oxygen supply. The rate of oxygen consumption is directly proportional with the intensity of the physical effort and expresses the limits of adaptation to the increase of the metabolic demand (Duţu \& Jienescu, 1984).

\section{Experimental Procedures}

Experimental diving's took place in the Hyperbaric Diving Centre, at high depth, using air as a respiratory mixture, and following two stages:

- 11 - 15.05.2015, at $50 \mathrm{mH}_{2} \mathrm{O}$ for 4 subjects;

- 01.09. - 30.10.2015 at $50 \mathrm{mH}_{2} \mathrm{O}$ for 12 subjects.

All the subjects were participants at the diver's professional training courses as second category underwater workers and experienced diver companions.

Each dive was preceded by the gathering of information regarding the subject's age, body weight, height and history of diving (immersion) Table no. 2 .

In order to measure FEV1, spirometric measurements have been performed at sea surface and immediately before and after each subject diving, using the spirometer presented by the Figure no. 1. Measurements were carried out three times, for each subject. The apparatus also recorded the values for the subjects' vital capacity which allowed us to calculate the Tiffeneau index (TF) as FEV1/VC formula (1).

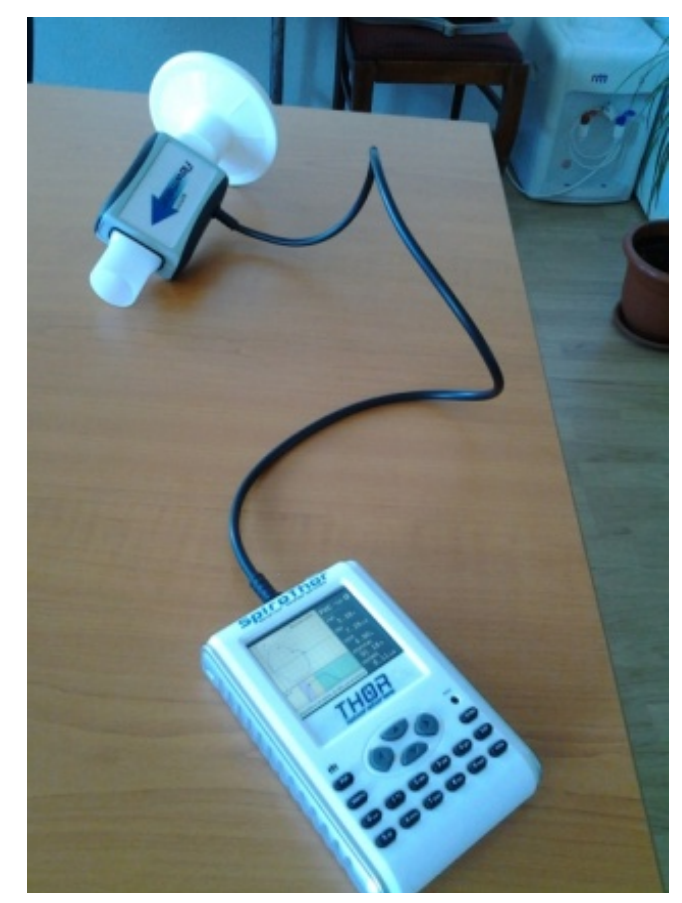

Figure no. 1 The spirometer 


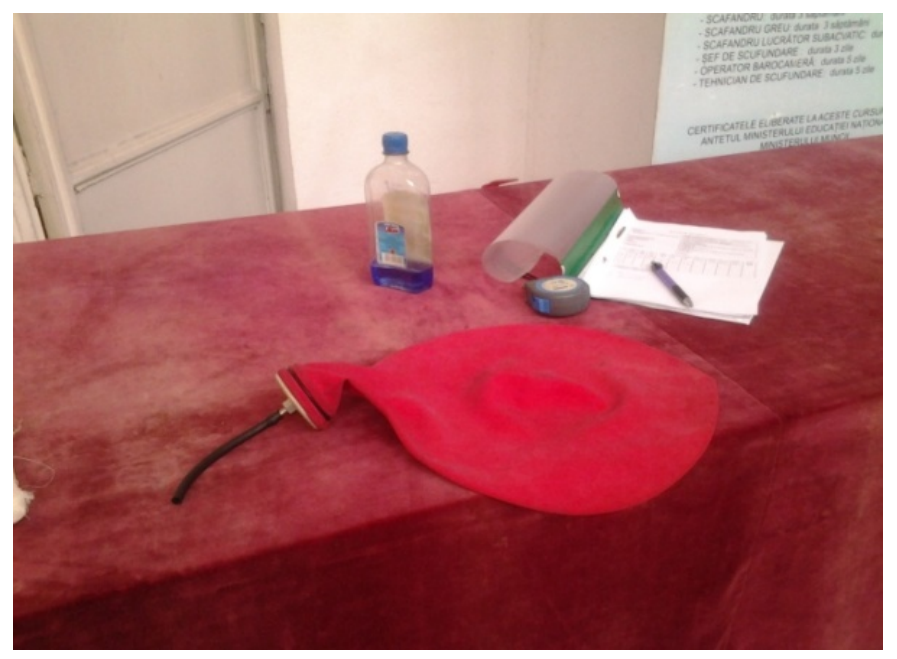

Figure no. 2 Gas sample collection bag

The divers expired air was collected before and after the dives using gas sample collection bags. The gas samples of expired air were studied using oxygen and carbon dioxide analysers from the pressurisation system, in order to measure the volumetric fraction of the gaseous contents, corresponding to each subject. For five minutes the divers have carried out vigorous exercises. After the physical effort the measurements were performed once again and the data representing each subject oxygen and carbon dioxide concentration were introduced in the table (Table no. 2). The table also contains the subject's personal data: age, body mass, diving history, smoker or non-smoker. We have used a tape measure and a gas sample collection bag for the next trial (Figure no. 2).
The divers have entered the dry hyperbaric chamber and after the pressurisation at $50 \mathrm{~m} \mathrm{H}_{2} \mathrm{O}$ they have expired, one by one, in the mask inside the discharge circuit. At the outer bottom of the discharge circuit the gas samples were collected in the bags and transported at the gas analysers of the Hyperbaric Laboratory. The gas analysis was performed and it was determined the volumetric fraction of oxygen and carbon dioxide for each subject expired air. For five minutes the divers have carried out vigorous exercises. After the physical effort the measurements were performed once again and the data representing each subject oxygen and carbon dioxide concentration from the expired air were recorded (Table no. 2).

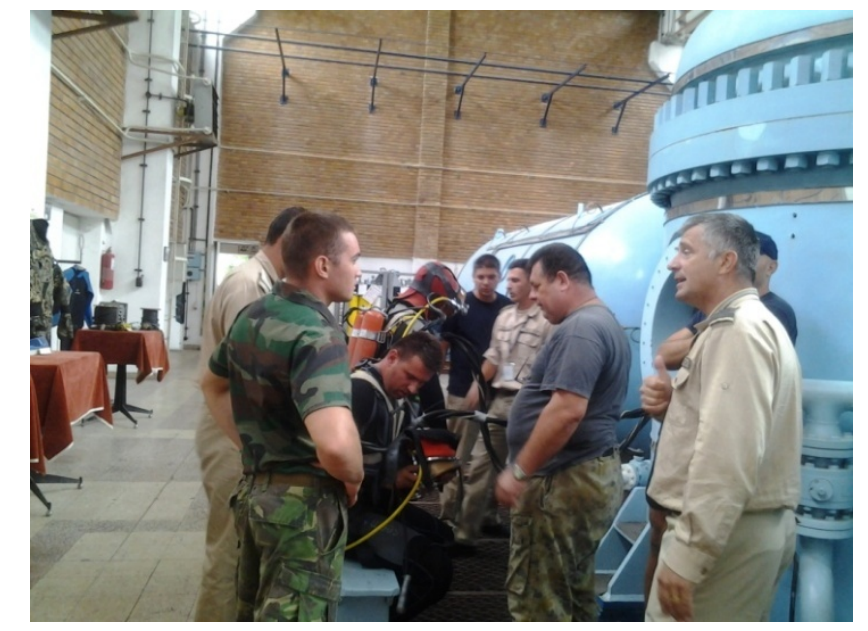

Figure no. 3 Equipping the divers and the collection of the samples before the dive 


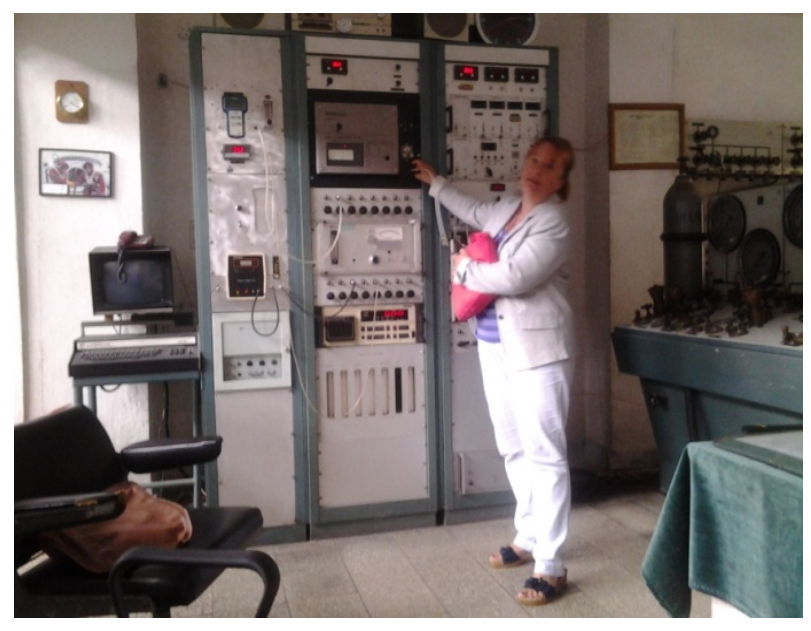

Figure no. 4 Analysis of the collected gases obtained at $50 \mathrm{~m} \mathrm{H}_{2} \mathrm{O}$

\section{Results}

\section{FVC S5}

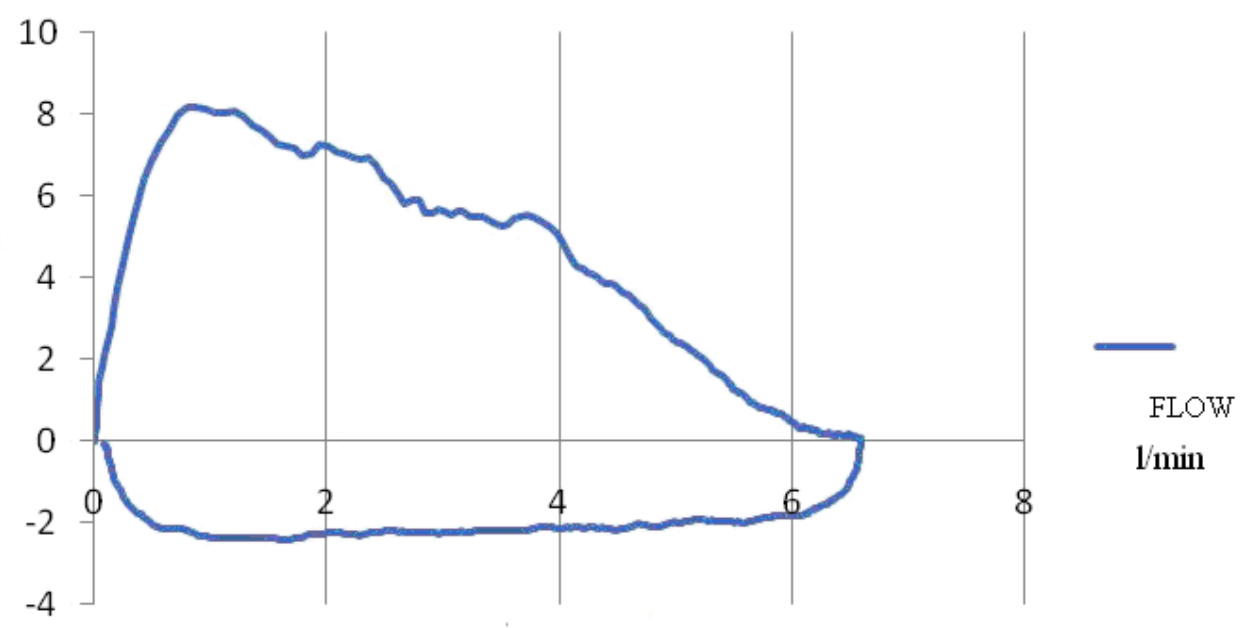

Figure no. 5 Forced vital capacity of the subject $n r 5$

Table no. 1

Vital capacity, FEV1, Tiffneau index in subjects $\mathrm{S1-S12}$

\begin{tabular}{|c|c|c|c|}
\hline Subject & CV [I] & FEV1 [I] & TF\% \\
\hline S1 & 6 & 5 & 84 \\
\hline S2 & 5.8 & 5 & 86 \\
\hline S3 & 5.8 & 5 & 86 \\
\hline S4 & 4.95 & 4.5 & 90 \\
\hline S5 & 6.5 & 6 & 92 \\
\hline S6 & 5.4 & 5 & 93 \\
\hline S7 & 5,8 & 5 & 86 \\
\hline S8 & 5.2 & 5.1 & 98 \\
\hline S9 & 4.8 & 4.2 & 88 \\
\hline S10 & 5.9 & 5.2 & 87 \\
\hline S11 & 6.8 & 5.8 & 85 \\
\hline S12 & 7 & 6 & 86 \\
\hline
\end{tabular}


Using spirometry we have determined the vital capacity and FEV1 from the diagrams recorded for each subject. The spirometer records diagrams and the corespondent values of the mentioned parameters (Figure no. 5).
In Table no. 2 we have the oxygen consumption and carbon dioxide production for the subjects S1-S4.

Results reflecting oxygen consumption and carbon dioxide production

for the subjects $S 1-S 4$, surface measurements

\begin{tabular}{|c|c|c|c|c|c|c|c|c|c|}
\hline Subject & $\begin{array}{c}\text { age } \\
\text { (years) }\end{array}$ & $\begin{array}{c}\text { Body } \\
\text { mass (kg) }\end{array}$ & $\begin{array}{c}\text { Height } \\
\text { (cm) }\end{array}$ & $\begin{array}{c}\% \text { Ox } \\
*\end{array}$ & $\begin{array}{c}\% \mathrm{CO}_{2} \\
*\end{array}$ & $\begin{array}{c}\text { \% Ox } \\
* * \\
\end{array}$ & $\underset{* *}{\mathbf{\%} \mathrm{CO}_{2}}$ & $\begin{array}{c}\text { Hist. } \\
\text { dive (hours) }\end{array}$ & Smoking \\
\hline 1 & 41 & 96 & 191 & 18.1 & 3.4 & 17.7 & 4 & 4000 & No \\
\hline 2 & 30 & 71 & 165 & 17.9 & 3.1 & 17.5 & 3.5 & 800 & No \\
\hline 3 & 32 & 79 & 173 & 18.2 & 2.8 & 18 & 3 & 1600 & No \\
\hline 4 & 27 & 76 & 174 & 18.1 & 2.9 & 17.6 & 3.4 & 400 & No \\
\hline
\end{tabular}

* Registered prior to the physical effort

** Recorded after the effort of diving
TIFFNEAU Index was calculated using the formula (1) for each one of the subjects. The results for the three measurements are presented in Table no. 1.

Table no. 3

The rate of oxygen consumption $R_{C O} O_{\text {ox }}$ prior to ${ }^{*}$ and after the physical effort ${ }^{*}$

\begin{tabular}{|c|c|c|c|c|c|c|c|c|c|}
\hline $\mathbf{S}$ & $\begin{array}{c}\mathbf{P E F}_{\mathbf{1}} \\
{\left[\mathbf{I}_{\mathbf{N}} / \mathbf{m i n}\right]}\end{array}$ & $\begin{array}{c}\mathbf{\%}^{*} \\
\mathbf{O x}^{*}\end{array}$ & $\begin{array}{c}\mathbf{\%}^{* * * *} \\
\mathbf{O x}^{* * *}\end{array}$ & $\begin{array}{c}\mathbf{\%} \mathbf{O x} \\
\mathbf{c o n s} .\end{array}$ & $\begin{array}{c}\mathbf{R}_{\mathbf{1}} \mathbf{C O x} \\
{\left[\mathbf{m l} \mathbf{N}_{\mathbf{N}} / \mathbf{m i n}\right]}\end{array}$ & $\begin{array}{c}\mathbf{P E F}_{\mathbf{2}} \\
{\left[\mathbf{I}_{\mathbf{N}} / \mathbf{m i n}\right]}\end{array}$ & $\begin{array}{c}\mathbf{R}_{\mathbf{2}} \mathbf{C O x} \\
{\left[\mathbf{m} \mathbf{I}_{\mathbf{N}} / \mathbf{m i n}\right]}\end{array}$ & $\begin{array}{c}\mathbf{P E F}_{\mathbf{3}} \\
{\left[\mathbf{I}_{\mathbf{N}} / \mathbf{m i n}\right]}\end{array}$ & $\begin{array}{c}\mathbf{R C} \mathbf{C}_{\mathbf{3}} \mathbf{O x} \\
{[\mathbf{m l} / \mathbf{m i n}]}\end{array}$ \\
\hline 5 & 78 & 18 & 17 & 1 & 780 & 66 & 660 & 72 & 720 \\
\hline 7 & 102 & 17 & 16.5 & 0.5 & 510 & 66 & 330 & 108 & 540 \\
\hline 8 & 84 & 17.5 & 17 & 0.5 & 420 & 90 & 450 & 96 & 480 \\
\hline 9 & 60 & 17 & 16.5 & 0.5 & 300 & 66 & 330 & 72 & 360 \\
\hline
\end{tabular}

The spirometer allowed the measurement of the ventilated air flows for each one of the divers, for each test. The rates of oxygen consumptions $\mathrm{RCOx}$ $\left[\mathrm{ml}_{\mathrm{N}} / \mathrm{min}\right]$, for each subject (Table no. 3) were calculated based on the formula (2) $R C O_{o x}\left[m l_{N} / \mathrm{min}\right]=P E F \bullet \% O_{x} \bullet 10$

$P E F[1 / \mathrm{min}]$ peak expiratory flow, is the maximum flow generated during a maximal forced expiration performed after a forced inspiration and can also be measured by spirometry.

Diagrams have been drawn, reflecting the variation of oxygen consumption rate on the ventilated air flow, after the physical effort, for each subject and by comparison among the subjects (Figure no. 6 and Figure no. 7) 


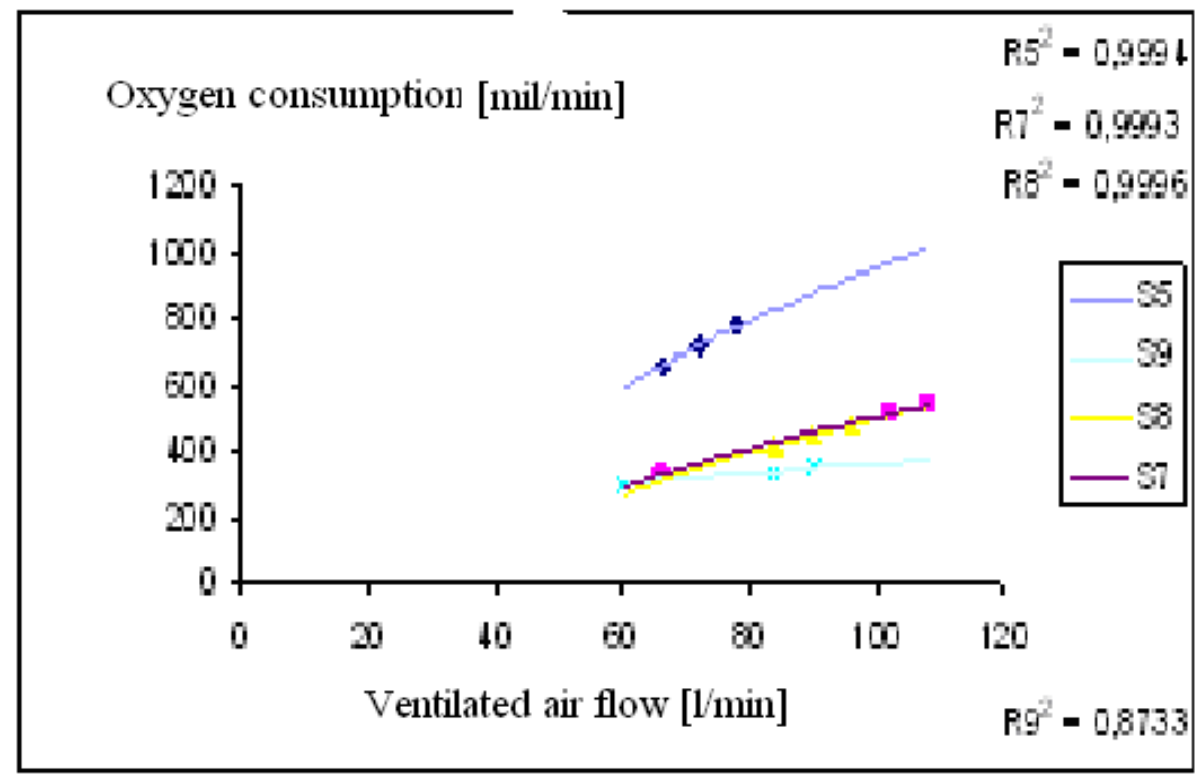

Figure no. 6 Oxygen consumption reported to the ventilated air flow for the subjects $S 5, S 7, S 8, S 9$

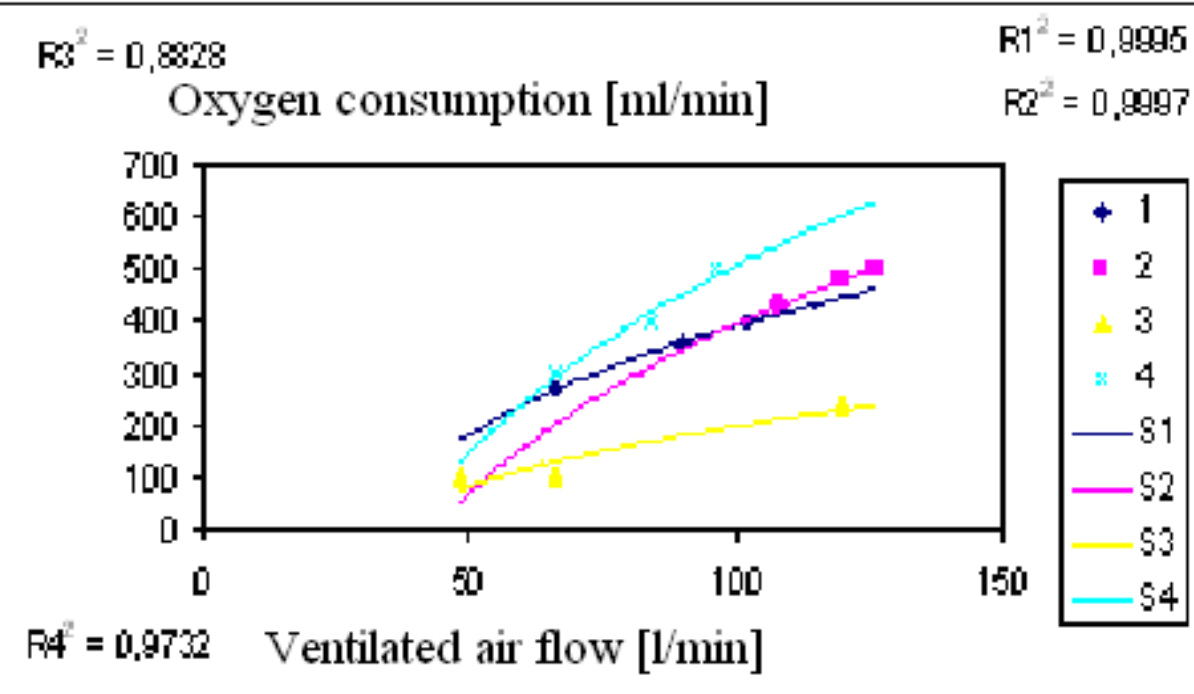

Figure no. 7 Oxygen consumption reported to the ventilated air flow for the subjects $S 1, S 2, S 3, S 4$

\section{Discussion}

The characteristics of divers' respiratory function in the hyperbaric environment depend on the type and intensity of the physical effort to be performed and also on the training programs that determine the individual capacity of adaptation to the effort. It is related to the increased demand for energy to fuel the tissues that determines the increase of the external breathing and also of the organism's gaseous exchanges.

The standardised values of men pulmonary vital capacity vary from 4-5 litters. In athletes these values must be about $10 \%$ higher. The subjects of our study presented a $\mathrm{VC}$ of 5-6 litters, proving that divers are well trained athletes with their training programs determining a raise of $20-25 \%$ compared to the standard values of the pulmonary vital capacity. 
Table no. 4

The rate of oxygen consumption and the ventilated air flow during the diving activities (US Navy, 2001)

\begin{tabular}{|l|c|c|}
\hline \multicolumn{1}{|c|}{ Divers type of activity } & \multicolumn{1}{c|}{$\begin{array}{c}\text { Average rate of oxygen } \\
\text { consumption [ml/min] }\end{array}$} & Ventilated air flow [1/min] \\
\hline Seated & 240 & 10 \\
\hline Sitting calm underwater & 400 & 12 \\
\hline Walking calm underwater & 580 & 15 \\
\hline $\begin{array}{l}\text { Mild activity in the hyperbaric } \\
\text { chamber }\end{array}$ & 700 & 18 \\
\hline Moderate walk on silt & 800 & 20 \\
\hline Moderate walk in the simulator & 1100 & 28 \\
\hline Power walking in the silt & 1200 & 32 \\
\hline Moderate swimming & 1400 & 38 \\
\hline Power swimming & 2500 & 60 \\
\hline
\end{tabular}

For untrained healthy individuals the average value for the TIFFNEAU index is $75-80 \%$, higher in children of about $80 \%$ and smaller of about $75-70 \%$ after the age of 60 . The TF values of the studied groups varied between $84-98 \%$ proving that in the first second of a forced expiration the divers can use most of the tidal volume allowing them to adapt more efficiently to the physical effort.

The average rate of oxygen consumption in relation to the ventilated airflow and the type of activity performed by the divers is classified according to the US Navy (Table no. 4).

The tested divers presented a respiratory rate lower than that measured at the surface, one of the reasons that allows them to adapt better to the physical effort, and the rate of oxygen consumption has reached values of $500-600 \mathrm{ml} / \mathrm{min}$. In the diagram presented in the Figure no. 6, for the subjects S5, S7, S8 and S9 it is to be noticed the influence of the divers physical constitution represented by the HIRTZ index (the difference between the thorax perimeter in inspiration and expiration), over the oxygen consumption rate. For the same ventilated air flow, of $801 / \mathrm{min}$, the subject S5 with a HIRTZ index of $10 \mathrm{~cm}$ the oxygen consumption is two times higher compared to the subject S9 whose HIRTZ index is of $4 \mathrm{~cm}$.
The tests performed in the Hyperbaric Laboratory were characterised by values of ventilated air flows with an average value of $84 \mathrm{l} / \mathrm{min}$, higher than the values presented by the US Navy manual (Table no. 4).

The activity of the divers had a moderate intensity, they had to assemble and disassemble a metallic construction, underwater at a depth of $50 \mathrm{~m}$. This is an exercise part of the training course. The mean value for the rate of oxygen consumption of the twelve tested divers was $433 \mathrm{ml} / \mathrm{min}$. This is half of the value from the US Navy manual for similar effort conditions and ventilation. These prove that the tested divers are very well trained, their metabolism is gradually increasing and the rate of oxygen consumption is in accordance with the physical effort.

\section{Conclusions}

Analyzing the diagram of the Figure no. 7 it is to be noticed that the subject S4 with the shortest diving experience (400 hours) has the higher oxygen consumption compared to the subjects with a 10 times longer diving experience. The best condition was proven by the subject $S 3,32$ years old and a diving experience of 1600 hours.

The results of the study emphasize that divers present individual variabilities in relation to the subjects physical constitution 
proving the necessity of individualised training programs.

Evaluating the divers effort capacity by the use of specific testing shows that proffessional divers represent a proffessional group that present vital capacities and forced expiratory volumes in the first second of a forced expiration higher than those of highly trained athlets (Table no. 1).

Increased metabolic demands expresed by the measure of divers oxygen consumption during specific testings, might induce a mechanical respiratory disfunction which is not to be during rest. This is the reason why the study of the divers ventilatory function during physical efort in hyperbaric condition might allow the prevention of the professional diseases and allow the understanding of the limits of adaptation.

In our country, for the first time, spirometry measurements were made during the diving (under pressure).

Knowing the influence of the risk factors mentioned in the paper, on the diver's breathing abilities, some of the specific occupational diseases will be avoided.

The results of the testings will be used by the specialists (doctors, engineers) of the Diving Center for the improvement of the human respiratory function in the hyperbaric environment by individually adapting the divers training programs and the increase of their physical performances contributing to better oxigenation during the effort.

\section{REFERENCES}

Boron, W. F., \& Boulpaep, E. I. (2005). Environmental Physiology, St. Louis, USA: Elsevier Saunders, 606-615.

Degeratu, M., Petru, A., Georgescu, Şt., \& Ioniţă S. (2008). Tehnologii hiperbare pentru scufundări unitare şi în saturaţie, Bucureşti: MATRIX ROM.

Duţu S., \& Jienescu, J. (1984). Ghid de investigaţii funcţionale respiratorii, Bucureşti: Medicală, 12-57, 124-130.

John, E. (2011). Guyton and Hall Textbook of Medical Physiology, St. Louis, USA: Elsevier Saunders, 465-472.

Tetzloff, K., Bettinghausen, E., Renter, M., Heller, M., \& Leplow, B. (1997). Risk factors for pulmonary barotraumas in divers, CHEST, Vol. 112, Issue 3.

US Navy (2001). Diving Manual, Revision 4, vol. 3, available at: https://www.scribd.com/document/37168793/Navy-diving-manual. 